\title{
Common and Country-Specific Uncertainty Fluctuations in Major Oil-Producing Countries: A Comparative Study
}

\author{
Refk Selmi ${ }^{1+}$, Jamal Bouoiyour ${ }^{2,1}$, and Shawkat Hammoudeh ${ }^{3,4}$ \\ ${ }^{1}$ ESC Pau Business School, France \\ ${ }^{2}$ Universite de Pau et des Pays de l'Adour, France \\ ${ }^{3}$ Drexel University, USA \\ ${ }^{4}$ Institute of Business Research, University of Economics, Vietnam
}

\begin{abstract}
In the wake of recent political developments worldwide, future oil supply prospects have become doubtful and uncertainty plays a non-negligible role in determining the dynamics of major macroeconomic variables. This study constructs a factor model with time-varying loadings to decompose the variance of important macroeconomic and financial series for the top 10 oil-producing countries into the contributions from country-specific uncertainty and common uncertainty. The relative importance of the uncertainty estimates in explaining volatility in production, investment, total exports, the exchange rate, and stock prices seems to vary over time, with evidence of alternating periods of high and low persistent uncertainty. Global uncertainty plays a primary role output growth, investment, exports, and stock prices in all countries. Globalization and trade openness contribute to amplifying the international transmission of volatility, explaining the increasing importance of the global uncertainty factor.
\end{abstract}

Keywords: Common uncertainty, country-specific uncertainty, top 10oil-producing countries, dynamic factor model JEL Classifications: C15, C32, E32, G11

Received 18 June 2019, Revised 9 August 2020, Accepted 20 August 2020

\section{Introduction}

Concerns about uncertainty have been exacerbated since the onset of the global financial crisis and the serial Eurozone crises. Ten years after the unprecedented 2008 global financial collapse, the world continues to remain in a state of great disequilibrium, both economically and geopolitically. The election of Donald Trump as the United States (US) president has created an unprecedented era of staggering uncertainty for the global economy, which was already fragile. Escalating trade tensions between the US and China, the rift between the US and Iran,

+Corresponding Author: Refk Selmi

Associate professor in Finance, ESC Pau Business School, Pau, France, Email: refk.selmi@esc-pau.fr

Co-Author: Jamal Bouoiyour

Associate Professor in Economics, Universite de Pau et des Pays de l'Adour, E2S UPPA, CATT, Pau, France; ESC Pau Business School, Pau, France, Email: jamal.bouoiyour@univ-pau.fr

Co-Author: Shawkat Hammoudeh

Professor in Financial Economics, Lebow College of Business, Drexel University, Philadelphia, USA; Institute of Business Research, University of Economics, Ho Chi Minh, Vietnam, Email: shawkat.hammoudeh@gmail.com 
and the recent Venezuela crisis and the resulting US sanctions have given rise to four prospective oil market scenarios. First, the failure of the US and China to establish a trade agreement has caused the imposition of additional tariffs, thereby resuscitating the specter of a long-running trade war. Investor sentiment and confidence would be highly impacted by a heightened trade war between the US and China. A deep belief exists that if these trade tensions continue to escalate, the world will be plunged into recession, leading to decreased growth in the demand for oil. Second, the escalation in the rift between the US and Iran shows no signs of abating. Iranian crude, which is facing dwindling demand in the market due to US sanctions, potentially poses enormous risks. Third, Venezuela is under punitive US sanctions as the US government urges all countries to cutoff oil production from Iran and Venezuela. Venezuelan oil exports have been damaged by the US embargo. Since the US is the largest purchaser of Venezuelan oil, Venezuela is highly sensitive to these cuts because of its high reliance on oil revenue. Fourth, persistently degrading conditions in Venezuela, intensified by recent nationwide power outages and escalating political tensions, have arisen due to concerns over supply disruptions in Iraq and Iran.

Therefore, a better understanding of how uncertainties about the economic outlook relate to macroeconomic variables in top oil-producing countries is quite relevant. Together, the uncertainty surrounding the aforementioned events might decide the fate of global oil markets. In this world of growing globalization, these events can have a global impact on investor sentiment and energy market performance.

Uncertainty can significantly affect the macro economy, depending on whether it reflects natural exogenous factors like natural disasters or geopolitical risks perceived as sources of political and macroeconomic fluctuations, or whether it emerges as an endogenous reaction to other potential macroeconomic drivers, including aggregate demand or supply shocks, thus exacerbating the impact of uncertainty. In fact, a high level of uncertainty can be transmitted through the macro economy by influencing the spending decisions of households and firms, leading to the suspension of consumption and investment and harming financial markets. Moreover, economic policy uncertainty might have a substantial impact on the appropriateness of economic policies. For example, economic downturns characterized by heightened uncertainty might necessitate deeper monetary policy stimulation responses to effectively support the economy.

Consequently, the evaluation of economic uncertainty and its possible effects is at the center of policymakers' attention (e.g., Bernanke, 2007; Kose \& Terrones, 2012; Haddow \& Hare, 2013; Carney, 2016). Individual and institutional investors, governments, and central bank officials have long considered policy uncertainty as an indispensable determinant of macroeconomic fluctuations (e.g., Arnold \& Vrugt, 2008; Bloom, 2009, 2014; Christiano et al., 2014). Arnold and Vrugt (2008) showed that a positive relationship exists between policy uncertainty and stock market volatility. Moreover, Kang et al. (2014) and Gulen and Ion (2016) indicated that great 
uncertainty yields a decline in investment and output growth. All countries confront shocks that might negatively affect their public finances. These shocks can limit revenue and cause inflationary pressure. In such scenarios, most countries must implement emergency fiscal tightening measures. Such emergency measures are likely to inhibit investment and economic development because they are usually based on measures that generate short-term financial benefits at the expense of long-term efficiency (Pástor \&Veronesi, 2013). Increased globalization stresses the paramount prominence of sound fiscal policy.

Our investigation is related to existing literature that focuses on the economic, macroeconomic, and financial uncertainties specific to certain developed economies and those that are common to a wide group of economies (e.g., Aloui et al., 2016; Balcilar et al., 2016; Beckmann et al., 2018; Bouoiyour et al., 2018). The present research seeks to assess the macroeconomic impact of country-specific and common uncertainties in selected top oil producers that are subject to uncertainty from multiple sources, as previously explained. At this stage, it must be emphasized that this issue has been explored solely for the Organisation for Economic Co-operation and Development (OECD)countries. Mumtaz and Thedoridis (2017) decomposed the volatility of real economic activity, inflation, and other financial series for 11 OECD countries into the contribution from country-specific uncertainty and the contribution common to all OECD countries under study. In the same context, Mumtaz and Musso (2018) disentangled the variance of a wide set of macroeconomic and financial variables for 22 OECD countries into contributions from country-specific uncertainty, region-specific uncertainty, and global uncertainty. They found that all uncertainty estimates play a significant role in explaining the volatility of real economic activity, inflation, interest rates, stock prices, and exchange rates for most countries, but as time passes, the effect of common uncertainty is becoming stronger.

This study goes beyond analyzing only the impact of structural oil price shocks on economic uncertainty by exploring the dynamic impacts of country-specific and common uncertainties on a wide set of macroeconomic and financial series in the 10topoil-producing countries. As far as we are aware, this is the first study that estimates the role of macroeconomic uncertainty in driving oil-dependent countries and aspires to explain the time variation in the contributions of distinct uncertainty types. Multiple studies have touched upon the interdependence between uncertainty and oil prices. Nevertheless, they mostly concentrate on oil price uncertainty rather than macroeconomic uncertainty (e.g., Pindyck, 2004; Bredin et al., 2011; Elder \& Serletis, 2010). Although prior studies have been useful for gaining insight into the sources of shocks under lying oil price movements, these analyses were not well-suited to uncovering the contributions from country-specific and common uncertainties for oil-producing countries. We focus on the top 10oil-producing countries, which account for more than $80 \%$ of the total world's crude oil production, as we believe that understanding the responses of these countries to common and country-specific uncertainties is very important in terms of oil price forecasting 
and political and regulatory implications. Given the past history of oil supply disruptions resulting from several geopolitical events, oil market participants should assess the possibility of future disruptions and the possible consequences of such uncertainty. Those participants should consider the ability of non-affected oil producers to counterbalance a probable oil supply deficit. Our concern is not with how policymakers respond to oil price uncertainty as is often done in the literature, but with the evolving financial and macroeconomic effects of different uncertainty sources for the top 10 oil-producing countries (i.e., the US, Saudi Arabia, Russia, Iraq, Iran, Canada, China, the United Arab Emirates (UAE), Kuwait, and Venezuela, in this order1)).

To the best of our knowledge, one aspect of common uncertainty has remained relatively unaddressed in the case of oil-producing countries that have a large impact on oil prices and the global economy.2) The noticeable increase in oil price volatility over the past decade has sparked an intensive debate about its potential determining factors. Many studies indicate that excessive oil price fluctuations are explained by the interplay between oil supply and demand (e.g., Baumeister \& Peersman, 2012; Hamilton, 2009; Kilian \& Murphy, 2010; Selmi et al., 2019), while others argue that speculation might play a significant role (Tang \& Xiong, 2011; Singleton, 2012). One factor that has been neglected in this debate is that during periods of high oil price volatility, uncertainty surrounding the macroeconomic outlook is typically quite high. It is claimed that heightened uncertainty can affect the decision-making behavior of economic agents (e.g., Bloom et al., 2007). Indeed, substantial uncertainty causes a delay in production or consumption decisions, thereby reducing quantity responses and increasing the price impact of the shocks. Uncertainty could significantly impact the responsiveness of oil prices and production to fundamental oil shocks, thereby changing oil price volatility. Significant changes in world oil prices over the past decade underscore how this uncertainty factor can influence oil prices and demonstrate the difficulty in projecting oil prices. It is also difficult to adequately identify all of the possible consequences related to the increased uncertainty surrounding unpredictable relations between the US, China, Iran, and Venezuela as well as developments in the Middle East (e.g., Saudi Arabia's fears over the revival of Iran's nuclear program). Moreover, public information regarding the future course of economic events can prompt greater price volatility, price drifts, and even booms and busts in prices (Singleton, 2012). New and accurate information about what contributes to country-specific and common uncertainty in the top 10 oil-producing countries can widely impact oil prices as investors learn about the economic environment. These considerations have motivated us to revisit the role of uncertainty in oil-dependent countries.

1) For more details about the percent share of the world's total crude oil production, please refer to Figure A1, Appendix.

2) It is well-known that oil price shocks affect the economy by changing relative prices and redistributing income, causing significant effects on consumption, investment, production, and welfare, which has drawn the attention of policymakers. 
Our findings indicate that both common uncertainty and country-specific uncertainty are likely to exert a non-negligible impact on financial and macroeconomic series in most cases, but such contributions vary over time.

This study is organized as follows. Section II introduces the empirical model and detailed information on the dataset. The results are summarized in Section III. Section IV discusses the main findings and concludes.

\section{The Empirical Model and the Data}

Currently, the rising complexity of the data employed in research and business analytics requires flexible, robust, and scalable econometric tools. Accordingly, the present research performs relatively new techniques that meet these requirements. Specifically, to determine the country-specific and common or global uncertainty proxies, we apply a dynamic factor model with stochastic volatility and time-varying factor loadings. The factor model is denoted as:

$$
X_{i t}=B_{i}^{C} F_{t}^{C}+B_{i}^{G} F_{t}^{G}+\omega_{i t}
$$

where $X_{i t}$ is a panel of macroeconomic and financial data for the set of the top 10 oil-producing countries under analysis.

This panel of data is summarized by three main components: a set of factors common to all countries $\left(F_{t}^{G}\right)$, a set of country-specific factors $\left(F_{t}^{C}\right)$ for each country, and idiosyncratic components $\left(\omega_{i t}\right)$. The global and country-specific factors pursue vector auto regression (VAR) processes:

$$
\begin{aligned}
& F_{t}^{G}=C^{G}+\sum_{j=1}^{p} \beta_{j}^{G} F_{t-j}^{G}+\left(\Omega^{G}\right)^{1 / 2} \varpi_{t} \\
& F_{t}^{C}=C^{C}+\sum_{j=1}^{p} \beta_{j}^{C} F_{t-j}^{C}+\left(\Omega^{C}\right)^{1 / 2} \vartheta_{t}
\end{aligned}
$$

where $\varpi$ is the common factor in idiosyncratic volatility and $\vartheta$ is the country-specific factor in idiosyncratic volatility.

It must be emphasized that Equations (2) and (3) enable the global and cross-country factors to have a dynamic relationship. The idiosyncratic components have an AR transition equation denoted as: 


$$
\omega_{i t}=\sum_{j=1}^{J} \rho_{j} \omega_{i t-j} h_{i t}^{1 / 2}+\varepsilon_{i t}
$$

where $\varpi_{t}, \vartheta_{t}, \varepsilon_{i t} \cdot N(0,1)$; $\varpi$ corresponds to the common factor in idiosyncratic volatility and $\vartheta$ represents the country-specific factor in idiosyncratic volatility.

Based on Mumtaz and Thedoridis' (2017) study, we enable time-varying factor loadings. Collecting the factor loadings at time $t$ into matrix $B_{i t}=\left[B_{i t}^{G}, B_{i t}^{C}\right]$, the law of motion depicting their time variation can be expressed as follows:

$$
B_{i t}=B_{i t-1}+\left(Q_{i}^{B}\right)^{1 / 2} U_{t}
$$

where the error terms in Equations (2), (3), (4), and (5) are heteroscedastic. Following Mumtaz and Musso (2018), the error covariance matrices in VAR Models (2), (3), and (4) are denoted:

$$
\Omega_{t}^{J}=(A J)^{-1} H_{t}^{J}(A J)^{-1}
$$

where $J=G, C . A J$ are lower-triangular and $H_{t}^{J}$ are diagonal matrices given by:

$$
H_{t}^{J}=\operatorname{diag}\left(S_{K}^{J} \lambda_{t}^{J}\right)
$$

Time-varying volatility is detected by $\lambda_{t}^{J}$, with $S_{k}$ representing the scaling factors for $\mathrm{k}=$ $1, \ldots, \mathrm{K}$. The total volatility evolves as an AR (1) process expressed as follows:

$$
\ln \lambda_{t}^{J}=\alpha^{J}+\beta^{J} \ln \lambda_{t-1}^{J}+\left(Q^{J}\right)^{1 / 2}+\xi_{t}^{J}
$$

Equation (6) indicates that the volatility component detects the entire volatility in the orthogonalized residuals of the VAR model. As claimed by Carriero et al. (2015), common volatility can be defined as the average of the variance of the shocks with equal weight given to individual volatilities. At this stage, we should point out that the errors in these equations represent the shocks to global and country-specific factors. Therefore, $\lambda_{t}^{G}, \lambda_{t}^{C}$ ) detects the average volatility of the unpredictable part of the common and cross-country components. These volatilities can be considered as relevant indicators of the uncertainty associated with global and country-specific economic circumstances.

We suppose that the variance of the shocks to the idiosyncratic component to be heteroscedastic, 
with $h_{i t}$ evolving as a stochastic volatility process. We therefore have:

$$
\ln h_{i t}=a_{i}+b_{i} \ln h_{i t-1}+q_{i}^{1 / 2} \zeta_{i t}
$$

The structure of the model suggests that the unconditional variance of each variable can be expressed as a function of $\Omega_{t}^{J}(J=G, C)$ and $h_{t}$. Specifically,

$$
\operatorname{var}\left(X_{i t}\right)=\left(B_{i t}^{G}\right)^{2} \operatorname{var}\left(F_{t}^{G}\right)+\left(B_{i t}^{C}\right)^{2} \operatorname{var}\left(F_{t}^{C}\right)+\operatorname{var}\left(\omega_{i t}\right)
$$

where the variance terms in Equation (10) are measured by means of a standard VAR formula for unconditional variance. These variance terms are time-varying as they are functions of $\lambda_{t}^{G}, \lambda_{t}^{C}$ ), and $h_{i t}$.

Note that the volatility of each variable in our panel is determined by the uncertainty common to all countries, an uncertainty that is country-specific, and a residual term that captures data uncertainty. In another work, we assess how the volatilities of a set of macroeconomic and financial series (including real economic activity, investment to gross domestic product (GDP) ratio, exports to GDP ratio, exchange rates, and stock prices) are driven by common and cross-country uncertainties. The time-varying factor loadings enable us to examine the dynamic contributions of each component of uncertainty-global, country-specific, and idiosyncratic.

We use quarterly data on the top 10oil-producing countries, which account for over $80 \%$ of global crude oil production. In particular, we consider data for the US, Saudi Arabia, Russia, Iraq, Iran, Canada, China, the UAE, Kuwait, and Venezuela. Understanding whether the volatility of the oil and non-oil series is driven by common or cross-country uncertainty is of paramount importance for countries that depend substantially on oil and petroleum products, especially when their oil dependence has remained invariant over time. For each country under analysis, the data run from 1997Q1 to 2018Q4. Our attention is limited to this period because of the availability of oil-related financial and macroeconomic variables. These variables include real economic activity, investment to gross domestic product (GDP) ratio, exports to GDP ratio, real effective exchange rates, and stock prices. Quantifying the time-varying impacts of various types of uncertainty on the volatility of these five-time series and analyzing the transmission of uncertainty shocks between countries incorporates a rich information set and captures uncertainty along various dimensions for market participants. Table 1 provides a list of these time series and the data sources. 
Table 1. Data, definitions, and sources

\begin{tabular}{|c|c|c|}
\hline Variables & Definition & Links of data sources \\
\hline GDP & $\begin{array}{l}\text { The contribution of oil to real gross domestic } \\
\text { product(GDP). The composition of GDP by sector } \\
\text { of origin is available at Econstats or at the Central } \\
\text { Intelligence Agency. The distribution gives the } \\
\text { percentage contribution of each sector to total GDP, } \\
\text { including oil sector. }\end{array}$ & $\begin{array}{l}\text { Econstats:http://www.econstats.com/index_gl.htm } \\
\text { https://www.cia.gov/library/publications/the-world-factb } \\
\text { ook/fields/214.html }\end{array}$ \\
\hline INV & Oil investments to GDP. & $\begin{array}{l}\text { Bank for International Settlements and Brueguel } \\
\text { research: http://www.bruegel.org/datasets/ }\end{array}$ \\
\hline EXP & Oil exports to GDP. & Econstats: http://www.econstats.com/index_gl.htm \\
\hline REER & $\begin{array}{l}\text { The sectoral real effective exchange rate (REER), } \\
\text { in particular, the oil sector. }\end{array}$ & $\begin{array}{l}\text { Bank for International Settlements and Brueguel } \\
\text { research: http://www.bruegel.org/datasets/ }\end{array}$ \\
\hline SPI & $\begin{array}{l}\text { Disaggregated stock price index, in particular, the } \\
\text { oil sector. }\end{array}$ & Bloomberg: https://www.bloomberg.com/markets/stocks \\
\hline
\end{tabular}

Table 2 provides descriptive statistics on the quarterly returns of our variables of interest, which demonstrate that the average quarterly returns of all of the time series under analysisis positive. The real effective exchange rates and stock indices of most countries are characterized by high volatility (i.e., have strong standard deviations). The skewness coefficients of all variables are negative and the kurtosis coefficients above three, indicating that the probability distributions of the considered return series are skewed and leptokurtic, thereby rejecting normality. All of the return series are non-normal, as indicated by the Jarque-Bera test. 
Table 2. Descriptive Statistics Return Series

\begin{tabular}{|c|c|c|c|c|c|}
\hline & GDP & INV & EXP & REER & SPI \\
\hline \multicolumn{6}{|c|}{ UNITED STATES } \\
\hline Mean & 0.0345 & 0.0419 & 0.0223 & 0.0317 & 0.0359 \\
\hline Median & 0.0132 & 0.0189 & 0.0209 & 0.0254 & 0.0267 \\
\hline Std. Dev. & 0.0234 & 0.0145 & 0.0416 & 0.1452 & 0.1398 \\
\hline Skewness & -0.2456 & -0.1867 & -0.1423 & -0.1356 & -0.1672 \\
\hline Kurtosis & 4.1092 & 3.9168 & 3.6734 & 3.5542 & 4.1024 \\
\hline Jarque-Bera & 61.224 & 49.376 & 52.167 & 46.713 & 44.429 \\
\hline$p$-value & 0.0000 & 0.0001 & 0.0014 & 0.0009 & 0.0002 \\
\hline \multicolumn{6}{|c|}{ SAUDI ARABIA } \\
\hline Mean & 0.0148 & 0.0216 & 0.0265 & 0.0201 & 0.0345 \\
\hline Median & 0.0127 & 0.0186 & 0.0257 & 0.0228 & 0.0512 \\
\hline Std. Dev. & 0.0223 & 0.1134 & 0.0393 & 0.1214 & 0.1341 \\
\hline Skewness & -0.1950 & -0.0500 & -0.086 & -0.2017 & -0.0371 \\
\hline Kurtosis & 3.6266 & 3.6500 & 3.6753 & 4.1951 & 4.2356 \\
\hline Jarque-Bera & 24.778 & 11.263 & 11.493 & 15.855 & 13.892 \\
\hline p-value & 0.0138 & 0.0014 & 0.0068 & 0.0345 & 0.0039 \\
\hline \multicolumn{6}{|c|}{ RUSSIA } \\
\hline Mean & 0.0069 & 0.0148 & 0.0216 & 0.0265 & 0.0411 \\
\hline Median & 0.0047 & 0.0127 & 0.0186 & 0.0257 & 0.0321 \\
\hline Std. Dev. & 0.0118 & 0.1956 & 0.0310 & 0.1393 & 0.1156 \\
\hline Skewness & -0.3251 & -0.1950 & -0.0500 & -0.0863 & -0.0672 \\
\hline Kurtosis & 3.4754 & 3.6266 & 3.6500 & 3.6753 & 4.1024 \\
\hline Jarque-Bera & 19.328 & 24.778 & 11.263 & 11.493 & 19.052 \\
\hline p-value & 0.0114 & 0.0097 & 0.0693 & 0.0628 & 0.0234 \\
\hline \multicolumn{6}{|c|}{ IRAQ } \\
\hline Mean & 0.0037 & 0.0216 & 0.0265 & 0.0345 & 0.0148 \\
\hline Median & 0.0027 & 0.0186 & 0.0257 & 0.0512 & 0.0127 \\
\hline Std. Dev. & 0.0486 & 0.1134 & 0.0393 & 0.0341 & 0.1956 \\
\hline Skewness & -0.2351 & -0.0500 & -0.086 & -0.0371 & -0.1950 \\
\hline Kurtosis & 6.0366 & 3.6500 & 3.6753 & 4.2356 & 3.6266 \\
\hline Jarque-Bera & 78.682 & 11.2636 & 11.4933 & 13.892 & 24.778 \\
\hline $\mathrm{p}$-value & 0.0056 & 0.0014 & 0.0068 & 0.0039 & 0.0097 \\
\hline \multicolumn{6}{|c|}{ IRAN } \\
\hline Mean & 0.0061 & 0.0451 & 0.0301 & 0.0098 & 0.0103 \\
\hline Median & 0.0055 & 0.0299 & 0.0345 & 0.0426 & 0.0127 \\
\hline Std. Dev. & 0.0932 & 0.1413 & 0.0311 & 0.0301 & 0.0456 \\
\hline Skewness & -0.1567 & -0.1176 & -0.0707 & -0.0255 & -0.0691 \\
\hline Kurtosis & 4.1092 & 4.2456 & 4.1567 & 4.5678 & 3.8192 \\
\hline Jarque-Bera & 23.843 & 19.883 & 22.982 & 18.795 & 25.678 \\
\hline$p$-value & 0.0000 & 0.0002 & 0.0004 & 0.0000 & 0.0003 \\
\hline
\end{tabular}


Table 2. Continued

\begin{tabular}{|c|c|c|c|c|c|}
\hline & GDP & INV & EXP & REER & SPI \\
\hline \multicolumn{6}{|c|}{ CANADA } \\
\hline Mean & 0.0345 & 0.0621 & 0.0913 & 0.0513 & 0.0814 \\
\hline Median & 0.0047 & 0.0245 & 0.0711 & 0.0432 & 0.0333 \\
\hline Std. Dev. & 0.0672 & 0.0663 & 0.0810 & 0.1456 & 0.1193 \\
\hline Skewness & -0.1567 & -0.0876 & -0.3412 & -0.6123 & -0.1569 \\
\hline Kurtosis & 3.1789 & 4.0981 & 4.2341 & 4.1892 & 3.9123 \\
\hline Jarque-Bera & 36.897 & 33.145 & 24.986 & 29.404 & 25.134 \\
\hline p-value & 0.0067 & 0.0081 & 0.0014 & 0.0000 & 0.0038 \\
\hline \multicolumn{6}{|c|}{ CHINA } \\
\hline Mean & 0.0451 & 0.0337 & 0.0281 & 0.0510 & 0.0449 \\
\hline Median & 0.0234 & 0.0432 & 0.0319 & 0.0276 & 0.0411 \\
\hline Std. Dev. & 0.0415 & 0.0567 & 0.0489 & 0.1159 & 0.1423 \\
\hline Skewness & -0.2345 & -0.1345 & -0.1671 & -0.1824 & -0.1455 \\
\hline Kurtosis & 5.1032 & 4.5617 & 4.9821 & 5.1146 & 3.9287 \\
\hline Jarque-Bera & 36.821 & 45.125 & 59.130 & 67.227 & 34.891 \\
\hline $\mathrm{p}$-value & 0.0000 & 0.0000 & 0.0001 & 0.0042 & 0.0007 \\
\hline \multicolumn{6}{|c|}{ UAE } \\
\hline Mean & 0.0237 & 0.0599 & 0.0168 & 0.0810 & 0.0521 \\
\hline Median & 0.0227 & 0.0766 & 0.0808 & 0.0721 & 0.0598 \\
\hline Std. Dev. & 0.0486 & 0.0378 & 0.0458 & 0.0346 & 0.0192 \\
\hline Skewness & -0.2351 & -0.0380 & -0.1764 & -0.5006 & -0.1783 \\
\hline Kurtosis & 6.0366 & 4.6392 & 4.5175 & 4.6639 & 3.8523 \\
\hline Jarque-Bera & 78.682 & 11.439 & 15.855 & 24.822 & 29.076 \\
\hline $\mathrm{p}$-value & 0.0003 & 0.0001 & 0.0000 & 0.0000 & 0.0000 \\
\hline \multicolumn{6}{|c|}{ KUWAIT } \\
\hline Mean & 0.0411 & 0.0168 & 0.0345 & 0.0414 & 0.0503 \\
\hline Median & 0.0321 & 0.0808 & 0.0225 & 0.0381 & 0.0476 \\
\hline Std. Dev. & 0.0156 & 3.0458 & 0.0991 & 0.1292 & 0.1438 \\
\hline Skewness & -0.0672 & -0.1764 & -0.4516 & -0.3894 & -0.2578 \\
\hline Kurtosis & 4.1024 & 4.5175 & 4.1567 & 4.0234 & 3.9156 \\
\hline Jarque-Bera & 19.052 & 15.855 & 21.489 & 22.611 & 23.098 \\
\hline p-value & 0.0234 & 0.0000 & 0.0000 & 0.0000 & 0.0010 \\
\hline \multicolumn{6}{|c|}{ VENEZUELA } \\
\hline Mean & 0.0245 & 0.0291 & 0.0304 & 0.0312 & 0.0407 \\
\hline Median & 0.0211 & 0.0197 & 0.0205 & 0.0216 & 0.0389 \\
\hline Std. Dev. & 0.0345 & 0.0358 & 0.0429 & 0.1578 & 0.1891 \\
\hline Skewness & -0.4134 & -0.3179 & -0.1569 & -0.2672 & -0.1981 \\
\hline Kurtosis & 4.1578 & 3.6500 & 3.6753 & 4.1951 & 4.2356 \\
\hline Jarque-Bera & 29.832 & 10.923 & 14.553 & 24.618 & 25.092 \\
\hline $\mathrm{p}$-value & 0.0104 & 0.0115 & 0.0007 & 0.0052 & 0.0102 \\
\hline
\end{tabular}

Notes. Std. Dev. is an abbreviation ofstandard deviation; the p-value corresponds to the test of normality based on the Jarque-Bera test. 


\section{Empirical Results}

\section{A. Estimates of the components of uncertainty}

The uncertainty measure derived from the dynamic factor model is displayed in Figure 1, by the posterior estimates of the common standard deviation of shocks to global factors 3$)\left(\lambda_{t}^{G}\right)^{1 / 2}$. We interpret this as an uncertainty indicator that is common across the countries under consideration. The figure indicates that global recessions are preceded or accompanied by noticeable spikes in the global uncertainty factor. We clearly demonstrate that the measure of global uncertainty reaches its highest levels during the Asian financial crisis (July 1997), the global financial crisis (September 2008), China's economic slowdown (July 2015), as well as escalated US-China trade tensions (February 2018).

Figure 1. The posterior estimate of the common standard deviation of shocks to global factors

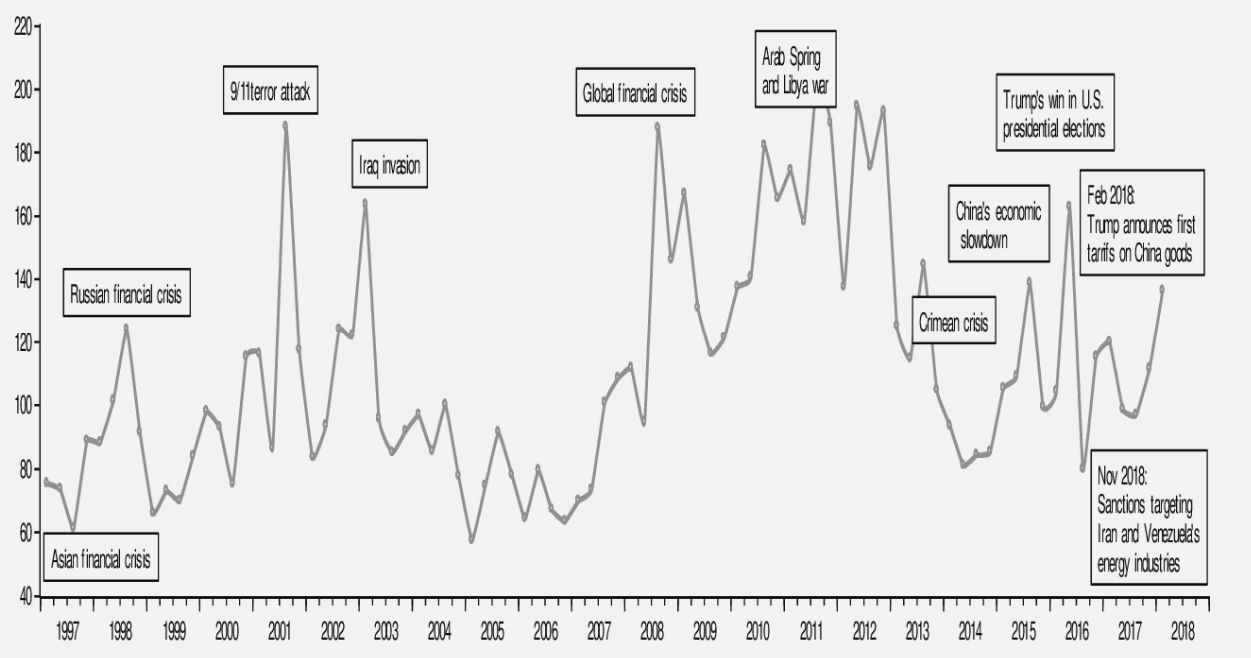

Summing up, several key geopolitical events relevant to demand- and supply-side oil dynamics are highlighted in the figure below, including: (i) the 2007-2008 global financial crisis; (ii) the Libyan war (2011); (iii) the 2014 Crimean crisis and ensuing Russian sanctions (October 2014); (iv) increased tensions between the US and China (since February 2018), which, in turn, drag down crude oil demand; (v) increased US-Iran tensions (November 2018); and (vi) the Venezuelan presidential crisis and US sanctions on Venezuela's petroleum and mining industries (December 2018). At this stage, it should be emphasized that it is still unclear whether

3) These factors correspond to various selected events related to either major economic events or associated with major geopolitical events with significant implications for global oil prices. 
Iran and Venezuela can mitigate the detrimental consequences of recent US sanctions by seeking partnerships with friendly countries. China and Russia continue to provide political and economic support to Venezuela, regardless of US sanctions. It is a matter of time until we have sufficient information about the consequences of US sanctions on Iran and Venezuela.

The posterior estimates of the common standard deviation of shocks to country-specific factors $\left(\lambda_{t}^{C}\right)^{1 / 2}$ for $\mathrm{c}=1, \ldots, 6$ are depicted in Figure 2. The cross-country estimates of macroeconomic uncertainty suggest that most recessionary periods are accompanied by a noticeable increase in country-specific macroeconomic uncertainty, unless they coincide with an increase in common uncertainty. Nevertheless, some periods of great uncertainty also coincide with other events that are not considered recessions. An example of such an episode is the Association of South East Asian Nations (ASEAN)-Canada Enhanced Partnership, which was adopted in Phuket, Thailand on July 2009, yielding a substantial increase in the Canadian uncertainty measure. For all country-specific uncertainty indicators, it is remarkable that the Asian financial crisis (July 1997), the global financial collapse (summer 2007), the second Persian Gulf war (March 2003), the Arab Spring (end of 2010), the Crimean crisis (February 2014), China's economic slowdown (July 2015), Trump's presidential win (November 2016), and the escalation of the US-China trade war (February 2018) led to the greatest volatility.

Not surprisingly, one evident cause of political disruption that has harmfully affected the oil market over the years is turmoil in the Middle East and North Africa (MENA) region. This can beattributed to the paramount importance of the region to the global oil supply. The MENA region includes some of the world's largest producers of oil, including Saudi Arabia, Iran, Iraq, the UAE, Kuwait, and Libya. The increased volatility of this region has prominent implications for the supply of oil. The stability of oil-producing countries is crucial to maintaining a global supply line and mitigating rising macroeconomic uncertainty. It must also be stressed that the Crimean action and resulting US sanctions have proven to be very expensive for Moscow.

In addition, oil investor sentiment and confidence are significantly impacted by the heightened trade war between the US and China. As the world's major importer of oil, China accounted for $20.2 \%$ of the world's crude oil imports in 2018, giving the country noticeable negotiating power in the global oil market (Bouoiyour \& Selmi, 2018). There is an atmosphere of high uncertainty over oil demand, stemming from increased doubts regarding a global collapse in economic activity. There is also a deep belief that if these trade tensions continue to escalate, the world will be plunged into recession, leading to lower growth in the demand for oil. Even though Canada was not the focus of Trump's anti-trade rhetoric during his 2016 presidential campaign, as a member of the North American Free Trade Agreement (NAFTA), if the new US president pursues renegotiation, it will prompt a high level of uncertainty for the USD 51 billion in goods that cross the US-Canadian border every month (Georges, 2017). Such 
observations highlight the importance of undertaking such an assessment using a historical sample spanning several years to evaluate the coincidence between uncertainty dynamics and recent developments from a broader perspective.

Figure 2. The posterior estimate of the common standard deviation of shocks to country-specific factors
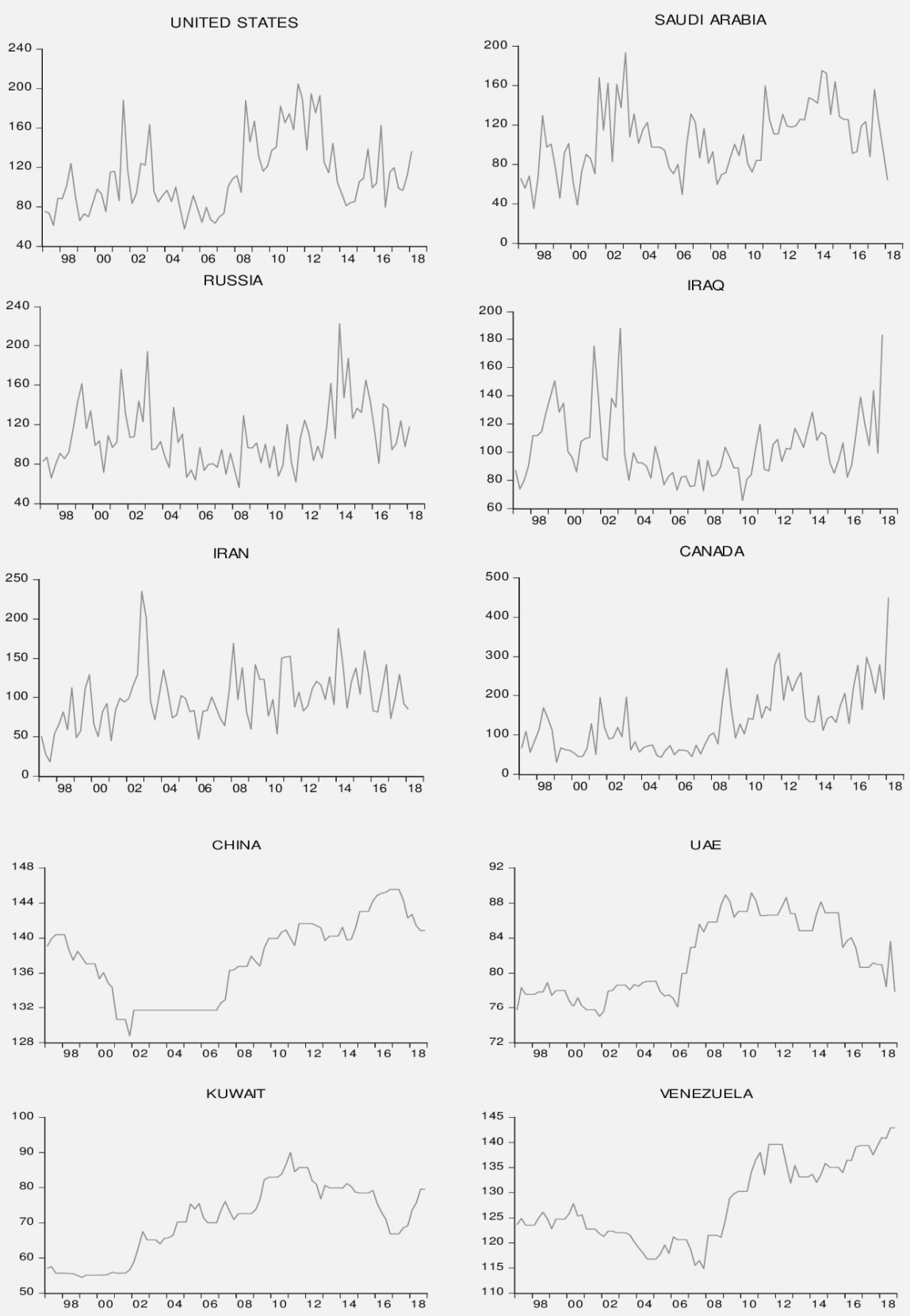


\section{B. Variance decomposition}

To examine the extent to which shocks to the various uncertainty components drive overall volatility in key macroeconomic and financial variables, forecast error variance decompositions are used. By using Equation (10), the unconditional variance of each variable is disentangled into the individual contributions of the various components of uncertainty (both global and country-specific) with the residuals capturing idiosyncratic, or variable-specific, volatility. Because the variances in the model are time-varying, the implied decomposition changes over different time horizons, and it is therefore instructive to investigate both the average contribution over the entire sample period and the evolution of these contributions over time.

\section{Entire sample}

Table 3 summarizes the average variance decomposition for the set of oil-specific macroeconomic and financial variables, namely, real economic activity, investment to GDP ratio, real exports to GDP ratio, the real effective exchange rate (REER), and stock prices. For most oil-producing countries, idiosyncratic uncertainty is the most important source of volatility in real economic activity, but the other two uncertainty components usually play a significant role. Regarding investment to GDP and exports to GDP, on average, for most countries, idiosyncratic uncertainty is the most prominent determinant of volatility, with common uncertainty representing the second-most important component. REER volatility seems to be driven by country-specific uncertainty and the idiosyncratic component; the contribution of common uncertainty appears to be relatively moderate. Moreover, stock price volatility also seems to be driven primarily by global uncertainty followed by the idiosyncratic uncertainty, for most countries with some exceptions (i.e., Iran, Iraq, the UAE, and Kuwait). 
Table 3. Contributions of the Common, Country-Specific, and Idiosyncratic Components to the Variance of Output Growth, Investments, Exports, Exchange Rate, and Stock Prices (Entire Sample)

\begin{tabular}{|c|c|c|c|c|c|c|c|c|c|c|c|c|c|c|c|}
\hline & \multicolumn{3}{|c|}{$\begin{array}{l}\text { Real economic } \\
\text { activity }\end{array}$} & \multicolumn{3}{|c|}{$\begin{array}{l}\text { Investments to } \\
\text { GDP }\end{array}$} & \multicolumn{3}{|c|}{ Exports } & \multicolumn{3}{|c|}{$\begin{array}{l}\text { Real effective } \\
\text { exchange rate }\end{array}$} & \multicolumn{3}{|c|}{ Stock price index } \\
\hline & $G$ & $C$ & $I$ & $G$ & C & $I$ & $G$ & C & $I$ & $G$ & $C$ & $I$ & $G$ & $C$ & $I$ \\
\hline UNITED STATES & $23 \%$ & $14 \%$ & $63 \%$ & $25 \%$ & $11 \%$ & $64 \%$ & $22 \%$ & $11 \%$ & $67 \%$ & $18 \%$ & $17 \%$ & $65 \%$ & $47 \%$ & $4 \%$ & $49 \%$ \\
\hline SAUDI ARABIA & $18 \%$ & $10 \%$ & $62 \%$ & $22 \%$ & $8 \%$ & $70 \%$ & $20 \%$ & $7 \%$ & $73 \%$ & $15 \%$ & $26 \%$ & $59 \%$ & $71 \%$ & $8 \%$ & $21 \%$ \\
\hline RUSSIA & $24 \%$ & $11 \%$ & $65 \%$ & $19 \%$ & $13 \%$ & $68 \%$ & $23 \%$ & $8 \%$ & $69 \%$ & $16 \%$ & $19 \%$ & $65 \%$ & $49 \%$ & $10 \%$ & $41 \%$ \\
\hline IRAN & $15 \%$ & $9 \%$ & $76 \%$ & $12 \%$ & $13 \%$ & $75 \%$ & $21 \%$ & $9 \%$ & $70 \%$ & $14 \%$ & $10 \%$ & $76 \%$ & $18 \%$ & $15 \%$ & $67 \%$ \\
\hline IRAQ & $12 \%$ & $15 \%$ & $73 \%$ & $16 \%$ & $14 \%$ & $70 \%$ & $13 \%$ & $16 \%$ & $71 \%$ & $19 \%$ & $15 \%$ & $66 \%$ & $17 \%$ & $22 \%$ & $61 \%$ \\
\hline CANADA & $21 \%$ & $6 \%$ & $73 \%$ & $29 \%$ & $11 \%$ & $60 \%$ & $26 \%$ & $9.5 \%$ & $64.5 \%$ & $20 \%$ & $27 \%$ & $53 \%$ & $51 \%$ & $6 \%$ & $43 \%$ \\
\hline CHINA & $39 \%$ & $8 \%$ & $53 \%$ & $33 \%$ & $9 \%$ & $58 \%$ & $41 \%$ & $13 \%$ & $46 \%$ & $17 \%$ & $24 \%$ & $59 \%$ & $47 \%$ & $3 \%$ & $50 \%$ \\
\hline UAE & $27 \%$ & $11 \%$ & $62 \%$ & $30 \%$ & $13 \%$ & $57 \%$ & $29 \%$ & $10 \%$ & $61 \%$ & $24 \%$ & $11 \%$ & $65 \%$ & $26 \%$ & $16 \%$ & $58 \%$ \\
\hline KUWAIT & $15 \%$ & $8 \%$ & $77 \%$ & $20 \%$ & $12 \%$ & $68 \%$ & $23 \%$ & $22 \%$ & $50 \%$ & $19 \%$ & $11 \%$ & $70 \%$ & $29 \%$ & $15 \%$ & $54 \%$ \\
\hline VENEZUELA & $16 \%$ & $5 \%$ & $79 \%$ & $14 \%$ & $8 \%$ & $78 \%$ & $17 \%$ & $6 \%$ & $77 \%$ & $14 \%$ & $18 \%$ & $68 \%$ & $73 \%$ & $9 \%$ & $18 \%$ \\
\hline
\end{tabular}

Notes. G: global or common uncertainty component; $C$ : Country-specific uncertainty component; I: Idiosyncratic component (residual).

\section{Time-varying contributions}

This study adopts the same strategy as Mumtaz and Musso (2018) by focusing on the average of the macroeconomic contributions of various uncertainty sources during different time periods. This could help capture the changes in contributions from one period to another. The factor model of Equation (10) is estimated via Gibbs sampling, thereby providing details on the contribution of each uncertainty component at all time points. Gibbs sampling is a Markov chain Monte Carlo algorithm for obtaining a sequence of observations which are approximated from a multivariate probability distribution. In doing so, we find that, on average, the macroeconomic uncertainty common to all countries has become gradually more pronounced whereas the country-specific and idiosyncratic uncertainty components are likely to play a less significant role.

Examining the contribution of uncertainty to volatility output growth, investments to GDP, exports to GDP, REER, and stock prices (Figures 3(a), 3(b), 3(c), 3(d), and 3(e), respectively), we note that for all of the considered countries, idiosyncratic uncertainty is the most important driver of volatility, with global uncertainty representing the second-most significant component in all cases. However, country-specific uncertainty appears to explain a relatively moderate fraction of volatility, except in Venezuela, where country-specific uncertainty seems to be very important. Moreover, we observe a marked elevation in the volatility of these time series in the last 10years, which can be explained by the dominance of global uncertainty. We also document a sharp decline in the contributing roles of the individual and idiosyncratic components (except with the REER).

Overall, the decomposition of uncertainty into different components (i.e., global, country-specific, 
and idiosyncratic) can be very useful and beneficial for the design of more appropriate regulatory frameworks and limit systemic risks during high-stress market scenarios. In fact, if the volatility of macroeconomic variables is determined mainly by the country-specific uncertainty component, then domestic policy measures might represent the most effective response to lessen the possible negative consequences. In contrast, when the macroeconomic variables are predominantly explained by common uncertainty, this might be beyond the control of national policymaking authorities if they act in isolation - they might need, under certain scenarios, to make coordinated policy responses on a global level. But with recent political developments that have exacerbated uncertainty (especially Trump's US presidential win) and Trump's neo-mercantilist attitude revolving around destroying trade deals and instituting tariffs, heightened US-China trade tensions, US sanctions on Venezuela's oil industry, and the escalation of the rift between the US and Iran, coordinating policy becomes difficult, if not impossible, to achieve.

If uncertainty is common for two or more countries that have a closer relationship (such as China-Russia, China-Venezuela, and Russia-Venezuela), then coordinating policy measures by national authorities seems to be warranted. As these countries become more interconnected thanks to globalization, they should strengthen prudential regulations to mitigate the rising risk of volatility spillover. In addition, as stock prices are most affected by global uncertainty, it is of paramount importance to foster more liquid capital markets to enhance emerging markets' resilience against shocks. 
Figure 3. Variance decompositions: Contributions of uncertainty components to the volatility of output growth, investments, exports, exchange rates, and stock prices over time 3(a). Output growth

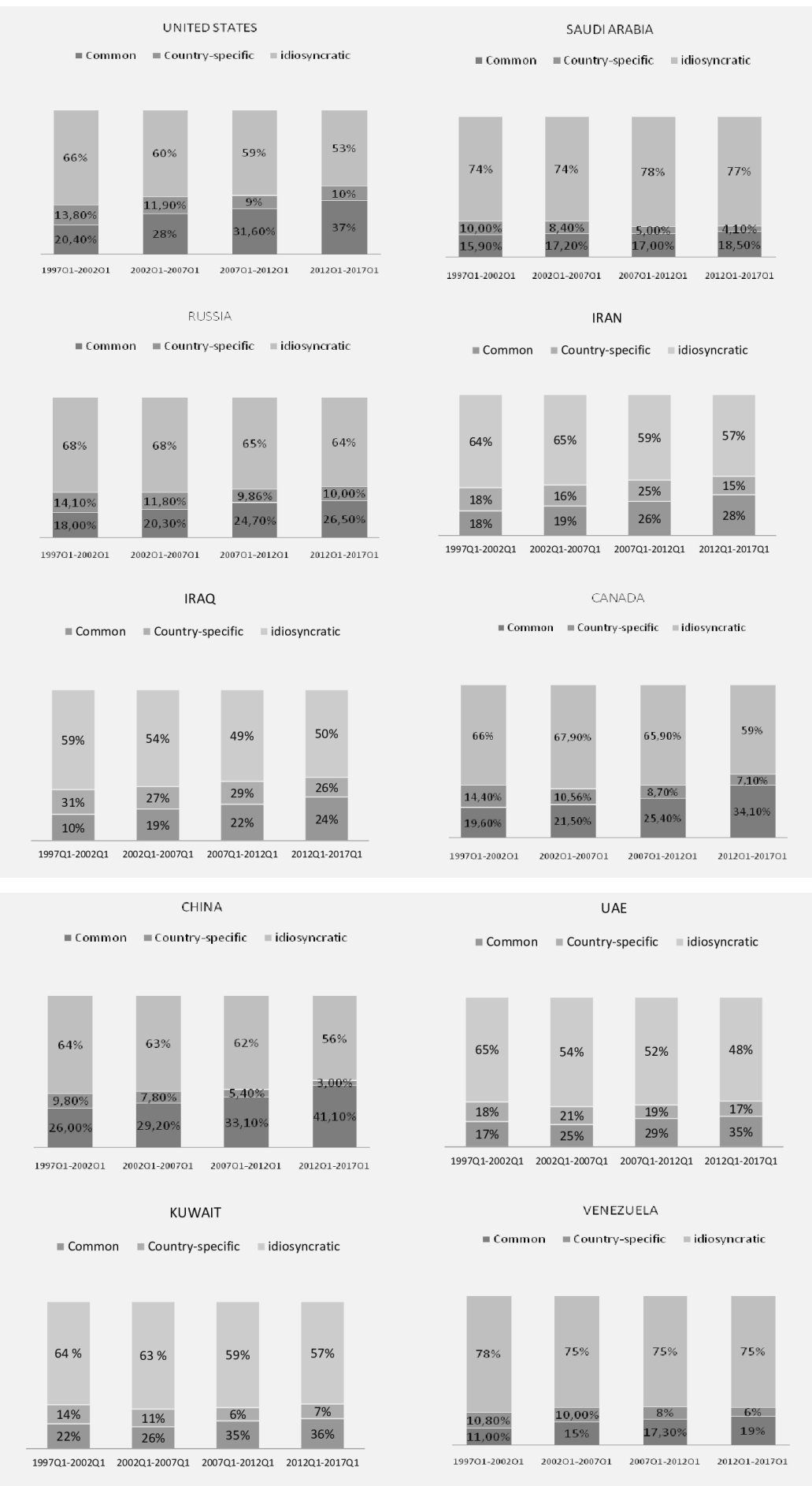


3(b). Investments to GDP

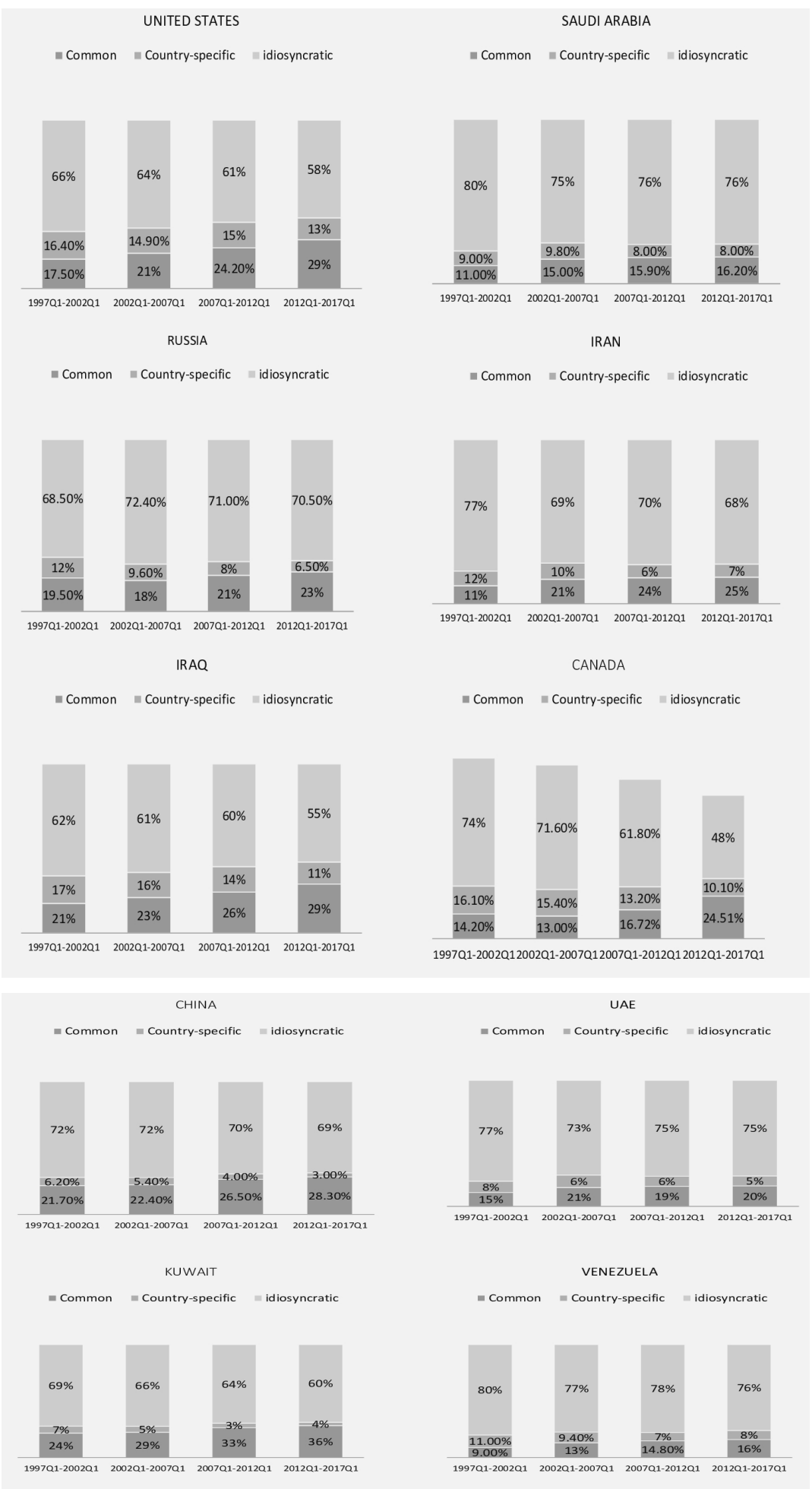


742 Journal of Economic Integration Vol. 35, No. 4

3(c). Exports to GDP

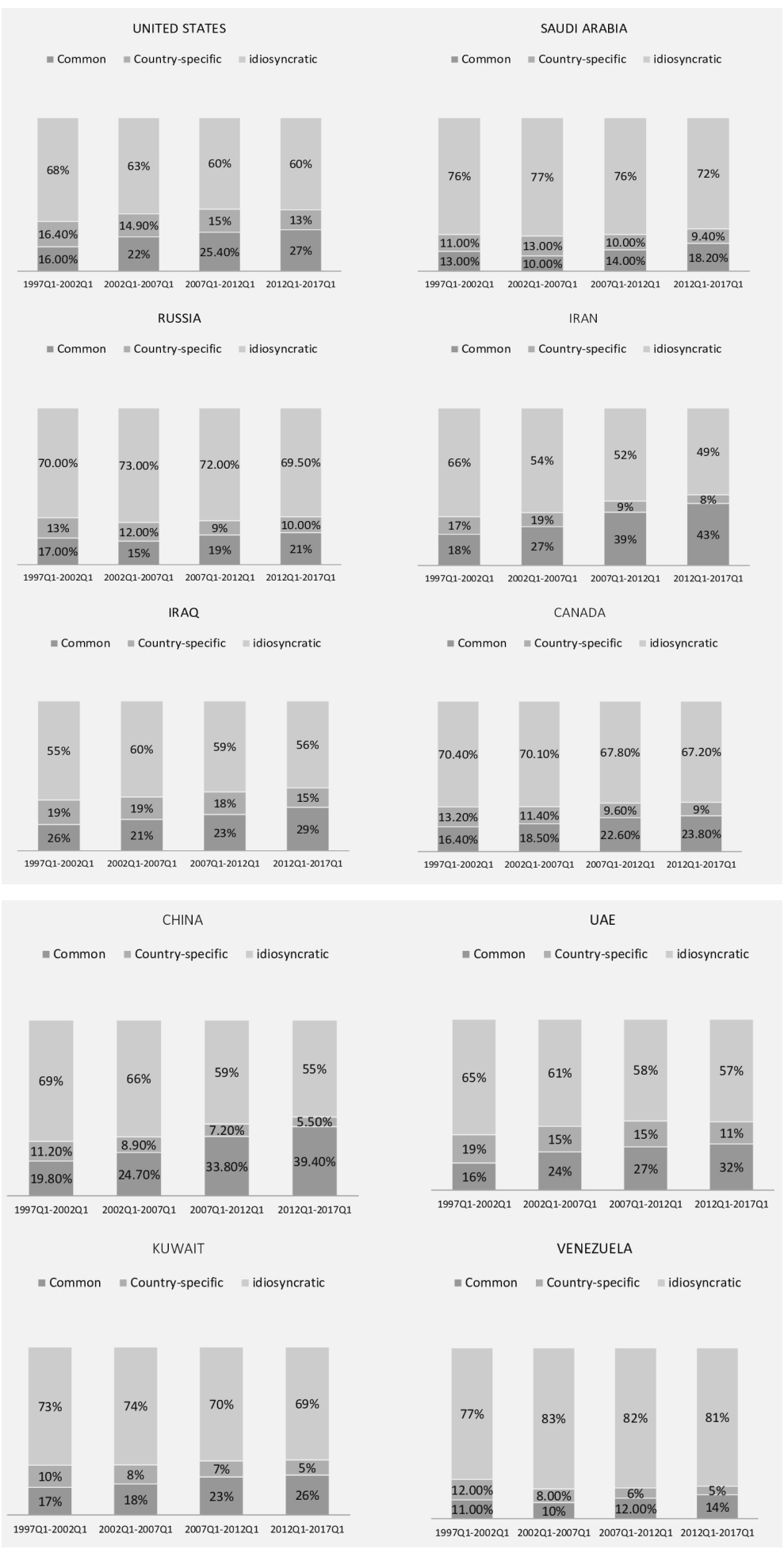


3(d). Real effective exchange rate

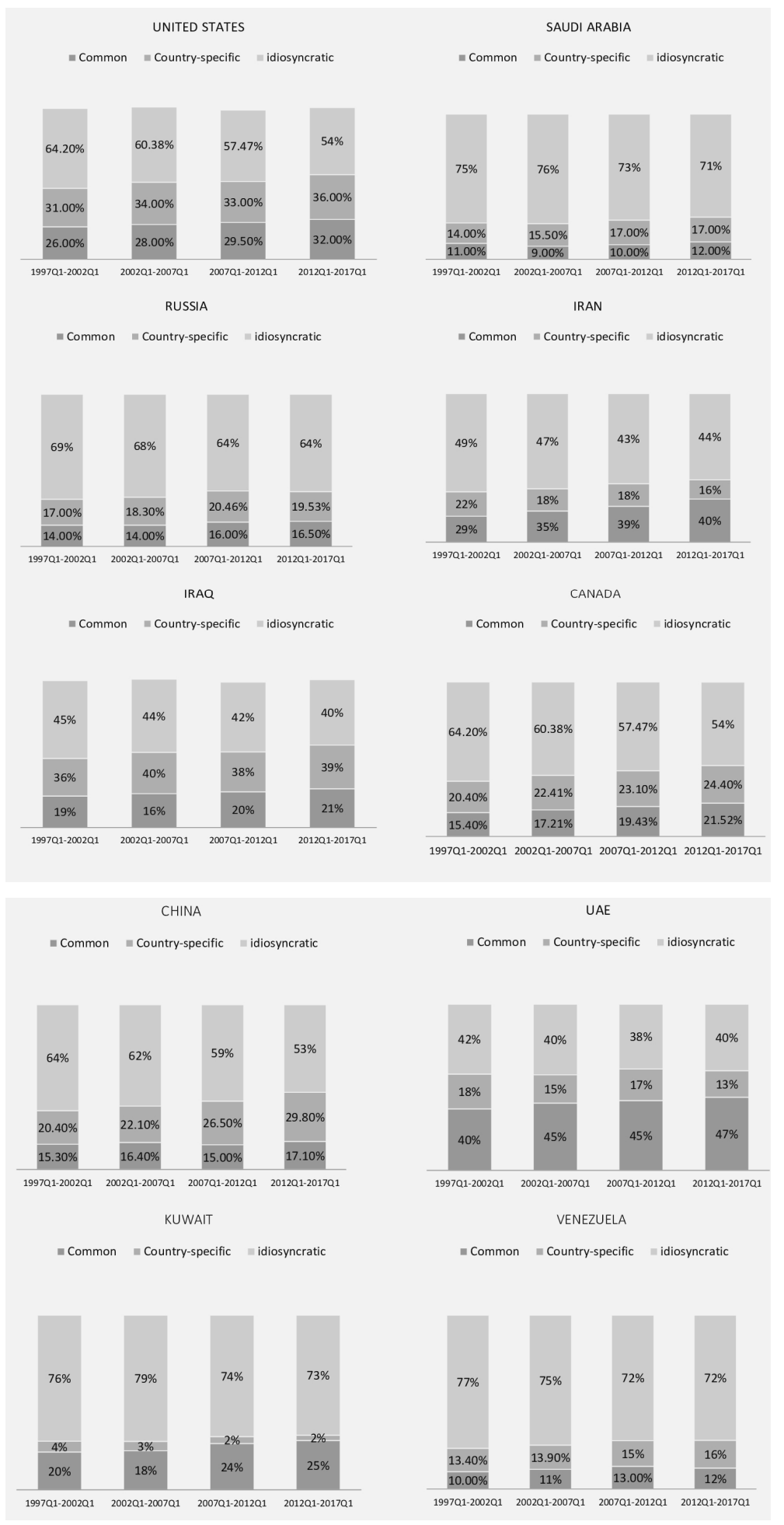


744 Journal of Economic Integration Vol. 35, No. 4

3(e). Stock prices

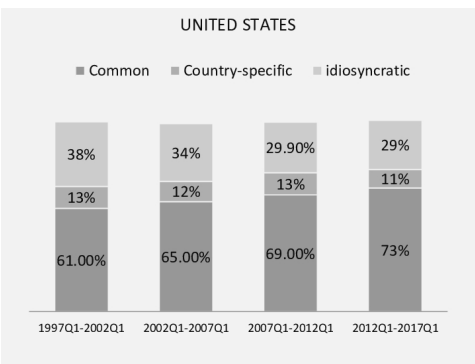

RUSSIA

- Common $=$ Country-specific $=$ idiosyncratic

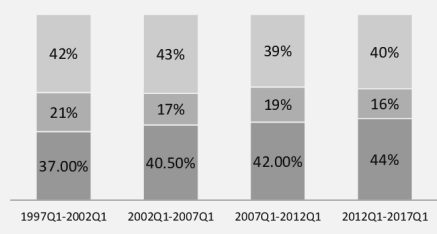

IRAQ

" Common $=$ Country-specific $=$ idiosyncratic

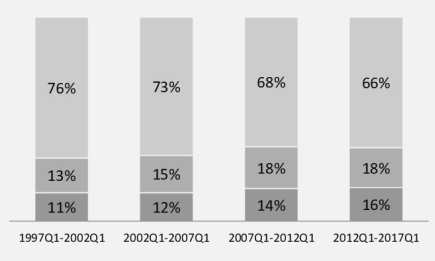

CHINA

= Common $=$ Country-specific $=$ idiosyncratic

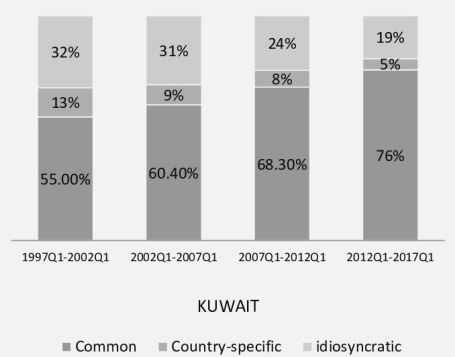

- Common $\|$ Country-specific $=$ idiosyncratic

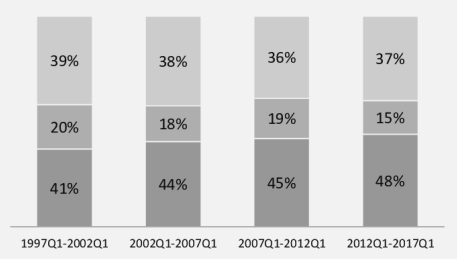

SAUDI ARABIA

ECommon $=$ Country-specific =idiosyncratic

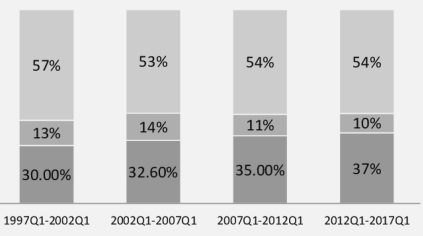

IRAN

= Common $=$ Country-specific =idiosyncratic

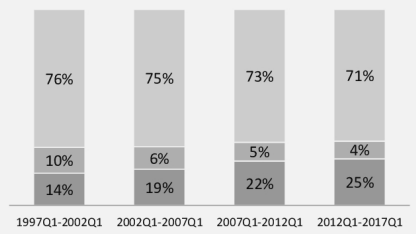

CANADA

=Common $=$ Country-specific = idiosyncratic

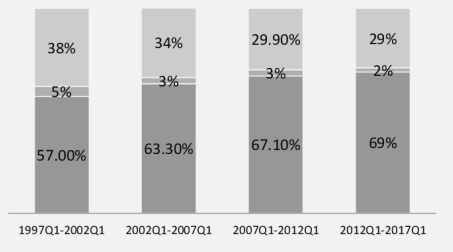

UAE

=Common $\|$ Country-specific $=$ idiosyncratic

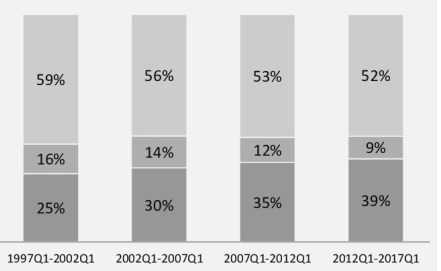

VENEZUELA

- Common = Country-specific =idiosyncratic

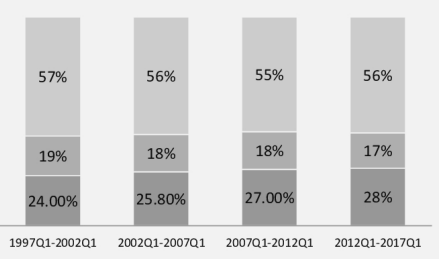


To ascertain the time-varying common and country-specific uncertainty impacts on the oil-related variables, we used a multiple structural change model developed by Bai and Perron (2003) to identify exogenous changes that might affect the time series under analysis. Table 4 reports the main findings. We note that most break points are observed with the onset of the global financial crisis (2007: Q4), the Crimean crisis (2014: Q1), the collapse of oil markets (2014: Q2), and Trump's win of the 2016 US presidential election (2016: Q4).

Table 4. Dates of Break Points in Time Series for the Top 10oil-producingcountries

\begin{tabular}{|c|c|c|c|c|c|}
\hline & GDP & INV & EXP & REER & SPI \\
\hline \multicolumn{6}{|c|}{ UNITED STATES } \\
\hline 1 & $2001: Q 3$ & $2007: Q 4$ & $2007: Q 4$ & $2007: Q 4$ & $2001: Q 3$ \\
\hline 2 & $2007: Q 4$ & $2016: Q 4$ & $2016: Q 4$ & $2016: Q 4$ & $2007: Q 4$ \\
\hline \multicolumn{6}{|c|}{ SAUDI ARABIA } \\
\hline 1 & $2007: Q 4$ & 2014 :Q2 & $2007: Q 4$ & $2014: Q 2$ & $2007: Q 4$ \\
\hline 2 & $2014: Q 2$ & & $2014: Q 2$ & & $2014: Q 2$ \\
\hline \multicolumn{6}{|c|}{ RUSSIA } \\
\hline 1 & $2007: Q 4$ & 2014 :Q2 & $1998: Q 3$ & $1998: Q 3$ & $2007: Q 4$ \\
\hline 2 & $2014: Q 1$ & & 2014 :Q1 & $2014: Q 1$ & $2014:$ : 1 \\
\hline \multicolumn{6}{|c|}{ IRAN } \\
\hline 1 & $2007: Q 4$ & 2018 :Q2 & $2016: Q 4$ & $2016: Q 4$ & $2016: Q 4$ \\
\hline 2 & $2018: Q 4$ & & $2018: Q 2$ & $2018: Q 2$ & $2018: Q 2$ \\
\hline \multicolumn{6}{|c|}{ IRAQ } \\
\hline 1 & $2003: Q 2$ & $2003: Q 2$ & $2003: Q 2$ & 2003 :Q3 & $2003: Q 2$ \\
\hline 2 & $2014: Q 2$ & & $2014: Q 1$ & $2014:$ : & $2014: Q 2$ \\
\hline \multicolumn{6}{|c|}{ CANADA } \\
\hline 1 & $2007: Q 4$ & $2007: Q 4$ & $2007: Q 4$ & 2014 :Q2 & $2007: Q 4$ \\
\hline 2 & $2014: Q 2$ & 2014 :Q2 & $2016: Q 4$ & $2016: Q 4$ & $2016: Q 4$ \\
\hline \multicolumn{6}{|c|}{ CHINA } \\
\hline 1 & 2015 :Q3 & $2007: Q 4$ & $2007: Q 4$ & 2015 :Q3 & 2015 :Q3 \\
\hline 2 & $2018: Q 2$ & $2015: Q 3$ & $2015: Q 3$ & $2018: Q 2$ & $2018: Q 3$ \\
\hline \multicolumn{6}{|c|}{ UAE } \\
\hline 1 & $2007: Q 4$ & $2007: Q 4$ & $2007: Q 4$ & $2007: Q 4$ & $2007: Q 4$ \\
\hline 2 & $2014: Q 2$ & $2014:$ : & $2014: Q 2$ & $2014: Q 2$ & $2014: Q 2$ \\
\hline \multicolumn{6}{|c|}{ KUWAIT } \\
\hline 1 & 2003:Q2 & 2014 :Q2 & 2003 :Q2 & 2003 :Q2 & $2007: \mathrm{Q} 4$ \\
\hline 2 & $2014:$ Q2 & & $2014: Q 2$ & $2014: Q 2$ & $2014:$ : 2 \\
\hline \multicolumn{6}{|c|}{ VENEZUELA } \\
\hline 1 & 2007:Q4 & 2018 :Q4 & $2007: Q 4$ & $2016: Q 4$ & $2007: Q 4$ \\
\hline 2 & 2017 :Q4 & & 2018 :Q4 & 2018 :Q4 & 2018 :Q4 \\
\hline
\end{tabular}

Notes. The break points are determined by sequential L +1 breaks vs. the $\mathrm{L}$ method of Bai and Perron (2003). Parameters of the break test are set as follows: Trimming 15\%, Maximum breaks 5, and Significance level 5\%. Statistics of the break test use the HAC covariance estimation, including pre-whitening with lag one, Quadratic-Spectral kernel, andtheAndrews bandwidth. The break test allows heterogeneous error distributions across the breaks. 
By considering the detected breaks, the key findings are preserved. In particular, global uncertainty is estimated to be the most significant determinant of volatility inoil-related output growth, investments, exports, and stock prices, with its average contribution increasing substantially after the global financial crisis. By contrast, exchange rate volatility is largely driven by individual country uncertainty. A country's social and economic outlook influences its national exchange rates. National governments can influence and regulate their exchange rates. However, in China, the Chinese government directly alters its exchange rate. A summary of the results is available upon request for interested researchers.

We have also assessed the occurrence of non-line arities in the developed common, countryspecific, and idiosyncratic volatility and various financial and macroeconomic variables (in particular, GDP, INV, EXP, REER, and SPI) using a BDS test (Brock et al., 1996) of non-linearity on the residuals recovered from the VAR models. The BDS test is the most popular test for non-linearity. It was originally designed to test a null hypothesis for an independent and identical distribution to capture non-random chaotic dynamics. When performed on the residuals from a fitted linear time series model, the BDS test can control for a possibly omitted non-linear structure. If the null hypothesis is rejected, this implies that the fitted linear model has been specified incorrectly. The test shows strong evidence of non-linearity, as it rejects the null hypothesis of an independent and identical distribution (i.i.d).

More precisely, the results suggest that the three uncertainty components and GDP, INV, EXP, REER, and SPI are non-linearly dependent, which is one of the indications of chaotic behavior and thus justifies the appropriateness of the time-varying factor model for assessing the time-varying contributions of different indicators of uncertainty to the set of financial and macroeconomic time series. To maintain the clarity of our presentation, the results are available upon request.

\section{Conclusions}

The present research builds a dynamic model with time-varying factor loadings and stochastic volatility to measure uncertainty that is common across the top 10 oil producers, who account for over $80 \%$ of global crude oil production, as well as country-specific uncertainty related to the individual oil producers. Both uncertainties can significantly impact the macro economy. We then quantify their influence in explaining volatility in the various financial and macroeconomic variables (in particular, overall output growth, investments to GDP, exports to GDP, the REER, and stock prices) and evaluate their changing roles over time.

We obtained three main findings. First, all of the uncertainty measures are characterized by alternating episodes of high and low risk. Second, the peaks in common and country-specific 
uncertainties coincide with turmoil in the Middle East region, the Crimean crisis, China's slowdown, Trump's win in 2016 US presidential elections, the current US-China trade war, escalated US-Iran tensions, and Venezuela's presidential crisis. Third, common uncertainty plays a foremost role output growth, investment, exports, and stock prices in all countries. But the importance of the different uncertainty components in explaining the volatility in the oil-related series appears to change over time and between the considered countries. The importance of global uncertainty as a driver of volatility in real economic activity, investments, exports, and stock prices can be explained by the increased financial liberalization, enhanced trade openness, the internationalization of national capital markets, and the reduction in barriers to foreign investment. The process of financial integration has been accompanied by an increase in international and regional trade agreements among these countries. While the progress of financial and trade integration has not been symmetrical across the economies under analysis, with some countries showing more dynamism than others, the growing importance of the global uncertainty factor in driving volatility in several macroeconomic and financial series underscores that these countries have become much more integrated and interdependent over the last 10years. In addition, most countries are driven by similar factors specific to their oil producer status, given their great dependence on oil and lack of diversification. Last but not least, the changing role of the various uncertainty components derived from the factor model to explain the volatility of several core financial and macroeconomic series suggests that monitoring both common and country-specific uncertainty is relevant to better understand developments in macroeconomic fluctuations and financial cycles and inform economic policymaking processes.

Recently, the agreement by the Organization of the Petroleum Exporting Countries (OPEC) and other countries to cut production (June 2019) underscores that geopolitics can have a significant impact on oil prices over the next few months and years. Furthermore, escalating US-Iran tensions show no signs of abating. Risks for oil supply disruptions could be more significant if Tehran takes action in trying to shut down the Straits of Hormuz, a very important transit point for the global crude oil trade. The widespread contamination of oil pumped through the Druzhba pipeline, the world's longest oil pipeline, as well as drone attacks on pumping stations on the East-West pipeline route in Saudi Arabia, have also added to global concerns.

Our results appear to be very timely and relevant for both individual and institutional investors as the global oil market continues to be rocked by unpredictable and extremely destabilizing events. With the many oil supply disruptions resulting from geopolitical events, being wellinformed is an effective defense. The dynamic factor model used in this paper helps risk-facing market participants by providing precise information over different time horizons. This, in turn, might help oil producers to counterbalance probable decreases in the supply of oil.

Before ending, it must be added that the oil markets are currently facing a perfect storm caused by the COVID pandemic. The supply and demand are moving against one another, 
leading to a growing pain on the oil industry and the stability of major oil producing-countries. In other words, the resulted decline in the price of oil puts several producing countries in precarious situations, due to the collapse of their revenues resulting from economic and financial instability in times of COVID-19. Today, these countries need their oil resources to respond to these exceptional economic risks caused by the pandemic. If some countries succeed even partially to manage the adverse effects of the pandemic due to the solidity of their foreign exchange reserves, it is obvious that if the situation persists, the consequences can only be more dramatic. This opens the door for further research on the COVID unparalleled shock and the future of global oil market.

\section{References}

Aloui, R., Gupta, R., \& Miller, S. M. (2016). Uncertainty and Crude Oil Returns. Energy Economics, $55,92-100$.

Arnold, I., \& Vrugt, E. (2008). Fundamental uncertainty and stock market volatility. Applied Financial Economics, 18(17), 1425-1440.

Bai, J., \& Perron, P. (2003). Computation and analysis of multiple structural change models. Journal of Applied Econometrics, 18, 1-22.

Balcilar, M., Gupta, R., \& Piedzioch, C. (2016). Does Uncertainty Move the Gold Price? New Evidence from a Nonparametric Causality-in-Quantiles Test. Resources Policy, 49, 74-80.

Baumeister, C., \& Peersman, G. (2012). The role of time-varying price elasticities in accounting for volatility changes in the crude oil market. Journal of Applied Econometrics, 28(7), 1087-1109.

Beckmann, J., Berger, T., \& Czudaj, R. (2018). Gold Price Dynamics and the Role of Uncertainty. Chemnitz Economic Papers.

Bernanke, B. (2007). Monetary policy under uncertainty, speech given at the 32nd Annual Economic Policy Conference, Federal Reserve Bank of St. Louis, 19 October 2007.

Bloom, N. (2009). The Impact of Uncertainty Shocks. Econometrica, 77(3), 623-685.

Bloom, N. (2014). Fluctuations in Uncertainty. Journal of Economic Perspectives, 28(2), 153-176.

Bloom, N., Bond, S., \& Van Reenen, J. (2007). Uncertainty and investment dynamics. Review of Economic Studies, 74, 391-415.

Bouoiyour, J., \& Selmi, R. (2018). The Heterogeneous Response of the Stock Market to China Slowdown and Oil Shocks: Evidence from G7 Countries. Journal of Economic Integration, 33(3), 488-513.

Bouoiyour, J., Selmi, R., \& Wohar, M. E. (2018). Measuring the response of gold prices to uncertainty: An analysis beyond the mean. Economic Modelling, 75, 105-116.

Bredin, D., Elder, J., \& Fountas, S. (2011). Oil volatility and the option value of waiting: An analysis of the G-7. The Journal of Futures Markets, 31(7), 679-702.

Brock, W. A., Dechert, W., \& Scheinkman, J. (1996). A test for independence based on the correlation dimension. Econometric Reviews, 15, 197-235. 
Carney, M. (2016). Uncertainty, the economy and policy, speech given at the Court Room, Bank of England, 30 June 2016.

Carriero, A., Mumtaz, H., Theophilopoulou A., \& Theodoridis, K. (2015). The Impact of Uncertainty Shocks under Measurement Error: A Proxy SVAR Approach. Journal of Money, Credit and Banking, 47(6), 1223-1238.

Christiano, L. J., Motto, R., \& Rostagno, M. (2014). Risk Shocks. American Economic Review, 104(1), 27-65.

Elder, J., \& Serletis, A. (2010). Oil price uncertainty. Journal of Money, Credit and Banking, 42(6), 1137-1159.

Georges, P. (2017). Canada's Trade Policy Options under Donald Trump: NAFTA's rules of origin, Canada-USsecurity perimeter, and Canada's geographical trade diversification opportunities (Working Paper No. 1707E). Department of Economics, Faculty of Social Sciences, University of Ottawa.

Gulen, H., \& Ion, M. (2016). Policy Uncertainty and Corporate Investment. Review of Financial Studies, 29, 523-564.

Haddow, A., \& Hare, C. (2013). Macroeconomic uncertainty: What is it, how can we measure it and why does it matter? Bank of England Quarterly Bulletin 2013 Q2.

Hamilton, J. D. (2009). Causes and consequences of the oil shock of 2007-08. Brookings Papers on Economic Activity, 215-259.

Kang, W., Lee, K., \& Ratti, R. A. (2014). Economic policy uncertainty and firm-level investment. Journal of Macroeconomics, 39, 42-53.

Kose, M., \& Terrones, M. (2012). How Does Uncertainty Affect Economic Performance? World Economic Outlook, October, 49-53.

Mumtaz, H., \& Theodoridis, K. (2017). Common and Country Specific Economic Uncertainty. Journal of International Economics, 105, 205-216.

Mumtaz, H., \& Musso, A. (2018). The evolving impact of global, region-specific and country-specific uncertainty (The ECB Working Paper Series No, 2147).

Pindyck, R. S. (2004). Volatility and commodity price dynamics. The Journal of Futures Markets, 24(11), 1029-1047.

Selmi, R., Bouoiyour, J., Hammoudeh, S., \& Wohar, M. (2019). What drive oil price jumps? Looking beyond the averages. The International Congress of Energy, Economy and Security, November 2019, Istanbul, Turkey.

Singleton, K. (2012). Investor flows and the 2008 boom/bust in oil prices (Working Paper). Stanford University.

Tang, K., \& Xiong, W. (2011). Index investing and the financialization of commodities (Working Paper). Princeton University. 


\section{Appendix}

Figure A1. Global oil shares of the top 10oil-producing countries

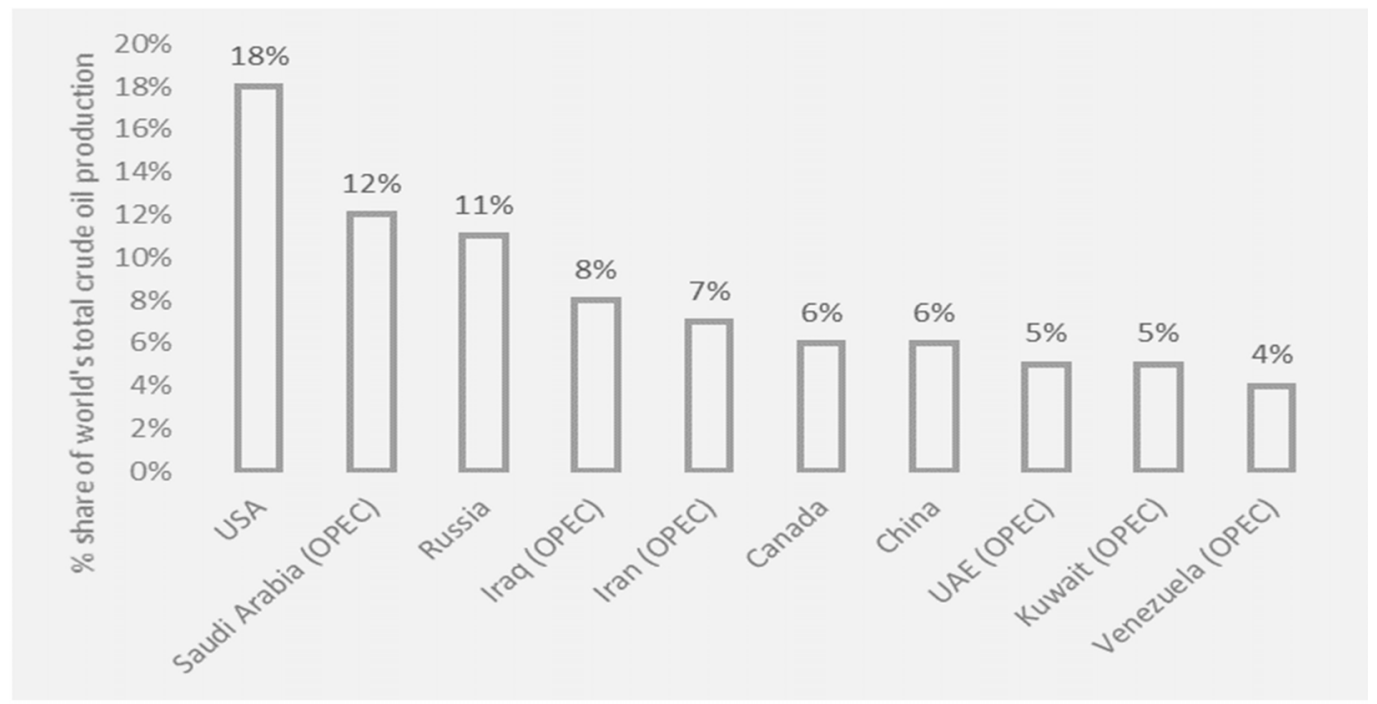

(Source) US Energy Information Administration; OPEC: The Organization of the Petroleum Exporting Countries. OPEC is an intergovernmental organization of 14 nations accounting for $44 \%$ of global oil production, giving them a significant influence on crude oil prices. 